\title{
DESENVOLVIMENTO PROFISSIONAL DOCENTE: A FORMAÇÃO INICIAL EM FOCO
}

\author{
DESARROLLO PROFESIONAL DOCENTE: LA FORMACIÓN INICIAL \\ EN FOCO
}

\section{PROFESSIONAL DEVELOPMENT TEACHER: THE INITIAL FORMATION IN FOCUS}

\author{
Adriana Patrício DELGADO ${ }^{1}$ \\ Carmem Silva SARTORI ${ }^{2}$ \\ Priscila Peres CAPEL ${ }^{3}$ \\ Regina Carminato NASCIMENTO ${ }^{4}$ \\ Verônica Santos Salles BARBOSA ${ }^{5}$
}

RESUMO: Identificar as percepções e dificuldades encontradas no cotidiano da profissão docente constitui o objetivo central desta pesquisa, que tem como tema a formação docente. Para tal, seguiu-se o seguinte percurso metodológico: elaboração dos instrumentos de pesquisa, seleção do campo e dos sujeitos (nove professores iniciantes que atuam no Ensino Fundamental I em escolas tanto públicas quanto privadas). Com base nos resultados foi possível identificar que: os momentos coletivos de discussão e reflexão na escola são exíguos; parte dos professores não tem clareza acerca dos saberes da profissão; não há uma política de incentivo à formação continuada; além da maioria reconhecer que o tempo da formação inicial foi insuficiente. Autores como Nóvoa, Pérez Gómez, Tardif e Zeichner forneceram o aporte teórico deste trabalho.

PALAVRAS-CHAVE: Formação inicial. Cultura escolar. Saberes docentes.

RESUMEN: Identificar las percepciones y dificultades encontradas en el cotidiano de la profesión docente constituye el objetivo central de esta investigación, que tiene como tema la formación docente. Para ello, se siguió el siguiente recorrido metodológico: elaboración de los instrumentos de investigación, selección del campo y de los sujetos (nueve profesores principiantes que actúan en la Enseñanza Fundamental I en escuelas tanto públicas y privadas). Con base en los resultados fue posible identificar que: los momentos colectivos de discusión y reflexión en la escuela son exiguos; parte de los profesores no tiene claridad sobre los saberes de la profesión; no hay una política de estímulo a la formación continuada; además de la mayoría reconocer que el tiempo de la formación inicial fue insuficiente. Autores como Nóvoa, Pérez Gómez, Tardif y Zeichner proporcionaron el aporte teórico de este trabajo.

${ }^{1}$ Universidade Nove de Julho (Uninove), São Paulo - SP - Brasil. E-mail: adrypatry@ hotmail.com

${ }^{2}$ Universidade Nove de Julho (Uninove), São Paulo - SP - Brasil. E-mail: adrypatry@ hotmail.com

${ }^{3}$ Universidade Nove de Julho (Uninove), São Paulo - SP - Brasil. E-mail: adrypatry@ hotmail.com

${ }^{4}$ Universidade Nove de Julho (Uninove), São Paulo - SP - Brasil. E-mail: reginacarminato@ hotmail.com

${ }^{5}$ Universidade Nove de Julho (Uninove), São Paulo - SP - Brasil. E-mail: adrypatry@ hotmail.com 
PALABRAS-CLAVE: Formación inicial. Cultura escolar. Saberes docentes.

ABSTRACT: Identifying the perceptions and difficulties encountered in the daily life of the teaching profession is the central objective of this research, which has teacher training as its theme. To do this, the following methodological course was followed: the elaboration of the instruments, the selection of the field and the subjects (nine beginner teachers who work in Elementary School I in public and private schools). Based on the results it was possible to identify that: the collective moments of discussion and reflection in the school are small; Some teachers are not clear about the knowledge of the profession; There is no policy to encourage continuing education; Besides the majority recognize that the time of the initial formation was insufficient. Authors like Nóvoa, Pérez Gómez, Tardif and Zeichner provided the theoretical contribution of this work.

KEYWORDS: Initial formation. School culture. Teacher knowledge.

\section{Introdução}

O desenvolvimento profissional docente tem se tornado uma questão preocupante e, consequentemente, alvo de debates ao longo de décadas. Sabe-se e se reconhece a importância da formação continuada no processo de aperfeiçoamento profissional, entretanto, há elementos cruciais que devem ser considerados e, devidamente tratados no percurso da formação inicial, tanto pelos professores formadores quanto pela instituição formadora.

Segundo Pérez Gómez (2001), os docentes têm encontrado dificuldades para responder profissionalmente as insistentes mudanças e renovações no âmbito escolar. Induzida pelas exigências do mercado, penetra nas escolas a obsessão pela eficiência notável e rápida. Devido ao excesso de responsabilidades, os professores perdem o foco de um ensinar contextualizado e refletido, para seguir normas e um modelo de ensino padronizado. Assim, as dificuldades para transformar a cultura do docente em práticas mais inovadoras e criativas se devem à deterioração de seu status e de sua consideração social.

Em boa parte dos contextos escolares, os docentes têm um papel muito reduzido no momento de tomada de decisões com relação ao sistema educativo, uma vez que trabalham em clima de isolamento, distanciamento e rivalidade, além do que não tem ideia clara quanto aos eixos que compõem o corpo teórico prático de sua atividade profissional. 
Segundo Roldão (2004), a profissão do professor não pode resumir-se à vocação, pois a profissionalidade plena necessita de avanço conceitual e claro, o que transcende o aspecto vocacional. Por isso, a necessidade dos professores assumirem-se como profissionais, compreendendo o sentido do desenvolvimento e como devem orientar-se na direção de uma profissionalidade reforçada, reconhecendo-se na função de ensinar juntamente com a ação de promover aprendizagens. Para isso, é necessário ter o conhecimento da teoria para indagar e iluminar a prática. Sendo assim, o cenário de praticismo e militância social, idealiza o professor como militante social, não valorizando sua função e saber.

Sobre os saberes profissionais dos professores e conhecimentos universitários, Tardif (2000) aborda questões que estão relacionadas à formação inicial dos professores e a profissionalização. Segundo o autor, querer estudar os saberes profissionais sem cotejá-los com uma situação de ensino é a mesma coisa que desejar estudar uma situação verdadeira de trabalho e de ensino sem levar em consideração a atividade do docente e os saberes mobilizados por ele.

O referido autor afirma que não se deve confundir os saberes profissionais com os conhecimentos transmitidos no âmbito de formação universitária. Ressalta ainda que, do ponto de vista metodológico é preciso saber se os pesquisadores de universidade querem realmente estudar os saberes profissionais de educação. Para isso, precisam sair de seus laboratórios e gabinetes, distanciarem-se de seus computadores e ir aos lugares em que os professores trabalham, para verdadeiramente observar a maneira como pensam, falam e atuam em sala de aula. Em sua definição, os saberes profissionais dos docentes são plurais e heterogêneos, além de variados e diversificados, pois provêm de diversas fontes, ou seja, os professores se baseiam em seu próprio saber vinculado à experiência de trabalho, na experiência de alguns professores e em tradições que estariam inerentes ao 'oficio do mestre'.

Este trabalho busca identificar as percepções e dificuldades encontradas no cotidiano da profissão docente, tendo como referência a visão de 09 professores iniciantes que atuam no Ensino Fundamental I (redes pública e privada e de um a cinco anos de docência). Um aspecto central de interesse desta pesquisa é saber em que medida os cursos de formação inicial têm contribuído para o exercício da prática profissional e, a partir das falas dos professores em exercício, fornecer elementos que provoquem reflexões e indagações nas instituições formadoras sobre o que se ensina e 
como se ensina. Para tanto, os sujeitos da pesquisa responderam a um questionário e foram submetidos a uma entrevista semiestruturada.

\section{Cultura da escola e cultura docente}

Para análise da cultura escolar, antes é preciso entender o que significa. De acordo com Pérez Gómez (2001): “[...] a escola, como qualquer outra instituição social, desenvolve e reproduz sua própria cultura. Entendendo por isso o conjunto de significados e comportamentos que a escola gera como instituição social". Desta forma, entende-se que cada escola possui uma organização própria, com tradições, costumes e rotinas singulares, as quais são conservadas pelos próprios indivíduos que dela fazem parte, tendendo a reproduzir o que já está pré-estabelecido, reiterando seu caráter conservador.

Ao ingressar em uma escola, o professor se depara com esta cultura que, na maioria das vezes, é diferente da sua cultura pessoal e profissional, ou seja, ocorre um choque entre as diferentes culturas. Nesta situação, o professor se vê condicionado a se adaptar à cultura da instituição para não ficar isolado e alheio aos acontecimentos, uma vez que é ele quem está chegando a um local onde tudo já está em andamento. Assim, ele consegue desenvolver um sentimento de pertença ao grupo e, é neste contexto, que irá desenvolver sua identidade profissional.

A respeito da cultura docente, Gomes (2009, p. 59) defende que:

De fundamental importância para o momento que atravessamos na Educação [...] é o fomento de culturas de colaboração entre os educadores, de maneira que exercitem a aprendizagem uns com os outros e troquem experiências, [...], a fim de porem-se no lugar do outro, admitirem os limites e possibilidades para operarem mudanças, propondo alterações no modo como se trabalha nas escolas, sem receituários ou padronizações.

A autora destaca ainda que haja vista a necessidade de comprovar que as situações que os professores enfrentam em seu cotidiano são as mesmas vivenciadas por seus parceiros e que, por isso, é de fundamental importância que estes unam esforços em vistas de melhorias.

Em entrevista, diante da seguinte questão: 'Onde e com quem você encontrou apoio para conversar e minimizar e/ou sanar as dificuldades e dúvidas encontradas no 
ambiente de trabalho?', foi possível identificar que oito dos nove professores entrevistados afirmam que encontraram apoio com os próprios colegas de trabalho.

Fato este que podemos comprovar diante da fala do professor D:

Foi na própria escola com uma professora que trabalha no mesmo ano que eu. Eu trabalho com $2^{\circ}$ ano. Ela percebeu que eu estava meio angustiado. E ela chegou várias vezes conversando comigo, aconselhando, me acalmando. E foi com ela que eu procurei desenvolver melhor o trabalho, ela foi me dando dicas porque ela já trabalhava na escola há um bom tempo e também já tem um conhecimento maior. Então foi com ela que eu fui tirando algumas dúvidas e tirando algumas angústias que eu estava em relação ao trabalho.

O mesmo reforça o professor G: "Acho que encontrei muito apoio com a coordenação e com as colegas da mesma série que escolhi trabalhar e até hoje nessa escola funciona assim, uma sempre apoia a outra quando temos dúvidas, angustias".

Ao ingressar em uma escola, o professor espera que ele seja bem recebido e acolhido pela equipe gestora e demais professores, além de receber instruções e matérias adequadas para o desenvolvimento do seu trabalho. Diante disso, foi realizada a seguinte pergunta aos professores entrevistados: 'A escola em que você iniciou a carreira docente ofereceu estrutura (espaços e materiais) adequada para o desenvolvimento do trabalho docente?', diante da qual as respostas obtidas foram bem variadas. A maioria dos professores concordou que existe uma boa estrutura e há materiais disponíveis para uso, porém, muitas vezes, estes não são adequados para a faixa etária e, geralmente, não há material suficiente para todos os alunos, além da dificuldade de acesso a alguns recursos materiais que poderiam auxiliar o professor em suas aulas; como é possível perceber através das falas dos seguintes professores.

Estrutura a escola tem, porém os materiais também, que são limitados, sempre com muita dificuldade de aproveitar deles, pois sempre tem algum imprevisto, ou não pode usar, ou estão quebrados, ou alguma coisa aconteceu e não tem como utilizar. $O$ espaço em si, a estrutura física da escola, é muito bom. É uma escola até grande, que tem uma estrutura de pátio, uma estrutura de sala, carteira em ordem, todas com boa manutenção. Porém os materiais que poderiam nos ajudar no conteúdo da aula do dia são sempre um pouco complicados de serem usados devido à todos os imprevistos que tem no dia-a-dia. (Professor D)

Dentro do possível né, espaço físico era bom material é aquele material básico né livro didático, paradidáticos, ah! Era o essencial 
né além da lousa, giz, apagador e somente isso não tinha nada tanto material quanto agora né que a gente tem um recurso a mais, mas no inicio era material básico mesmo. (Professor $\mathrm{H}$ )

De acordo com Pérez Gómez (2001), a cultura docente está relacionada aos métodos utilizados na classe, na qualidade, no sentido e na orientação das relações interpessoais, na definição de papéis e funções que desempenham, nos modos de gestão, nas estruturas de participação e nos processos de tomada de decisões. Porém, a cultura docente tem passado por momentos de tensão, pois os professores se veem sobrecarregados pelo excesso de responsabilidade, acompanhado pela pressão e urgência em atender às exigências do mercado, e a desconsideração social de seu trabalho, fatores que tem causado ansiedade, frustração, insatisfação profissional e desorientação.

Diante destas questões, é possível afirmar que só se pode entender a cultura docente, se primeiramente entender a cultura institucional. Afinal, cada escola tem uma cultura peculiar e cada docente tem sua própria cultura internalizada, que é constantemente influenciada pela cultura da escola à medida que o professor vivencia a rotina da instituição, se adaptando a ela, para assim desenvolver sua identidade profissional docente e, consequentemente, um sentimento de pertença ao grupo.

\section{Desenvolvimento Profissional Docente}

Pesquisar sobre os saberes docentes que servem de base para o ensino, sobretudo, a maneira como são vistos pelos professores, requer alguns elementos importantes à prática profissional docente. Segundo Tardif (2000, p. 06):

[...] em sua prática, os profissionais devem se apoiar em conhecimentos especializados e formalizados, na maioria das vezes, por intermédio das disciplinas científicas em sentido amplo, incluindo, as ciências naturais e aplicadas, mas também as ciências sociais e humanas assim como as ciências da educação.

Desse modo, os conhecimentos especializados devem ser alcançados por meio de uma formação de alto nível universitário, bem como, os conhecimentos que são voltados para a solução de situações problemas no cotidiano que de certa forma possa facilitar na aprendizagem dos alunos que se encontra com dificuldade. Assim, pode-se dizer que, existem diversos objetos, questões e problemas que estão relacionados à 
profissionalização do professor que devem ser levadas em consideração entre eles à autogestão dos conhecimentos adquirida com seus pares e o autocontrole da prática, pois a competência ou a incompetência de um professor somente podem ser avaliadas por seus pares.

Assim sendo, é necessário que a formação inicial proporcione fundamentos que oriente o professor a valorizar a necessidade de uma atualização permanente a fim de criar estratégias e métodos de intervenção, cooperação e, desse modo, promover uma integração interdisciplinar. De acordo com Imbernón (2011, p. 68):

A formação inicial deve dotar de uma bagagem sólida nos âmbitos cientifico, cultural, contextual psicopedagógico e pessoal que deve capacitar o futuro do professor ou professora a assumir a tarefa educativa em toda sua complexidade, atuando reflexivamente com flexibilidade e o rigor necessário, isto é, apoiando as suas ações em uma fundamentação válida para evitar cair no paradoxo de ensinar a não ensinar.

O autor ressalta ainda a importância de um currículo formativo que possa assimilar um conhecimento profissional básico que tanto promova experiências interdisciplinares quanto permita ao futuro professor maior integração entre as áreas dos conhecimentos e os procedimentos entre as diversas disciplinas com uma visão psicopedagógica, isto é, a integração e relação do conhecimento didático do conteúdo com o conhecimento psicopedagógico.

Destaca também a formação permanente do professor, pois segundo o autor, baseia-se na reflexão sobre sua própria prática como ao realizar a autoavaliação, e com isso, entenderem-se as capacidades, habilidades e questionamentos, tanto individuais como coletivos que possa orientar os professores ao desempenhar a sua profissionalização. Quando questionados em entrevistas sobre a carga horária do curso de graduação, assim como as disciplinas e conteúdos, se foram suficientes e adequados para atuação profissional, a maioria considera a carga horária da formação inicial boa e adequada, porém, em relação às disciplinas, vejam o que os professores declararam a esse respeito:

Então, eu acho assim, é muita teoria na faculdade e muitas delas nós não aplicamos aqui. Duas matérias que eu gostei muito da faculdade, que eu acho que foram as únicas que realmente foram muito úteis foram as de Matemática, que tem os jogos matemáticos, e a parte de alfabetização, e eu usei muito aqui na EMEF. Agora quanto aos outros conteúdos, é muita teoria e a gente não usa, realmente não 
usamos na sala de aula. Eu acho sim que pode ser modificado um pouco para uma forma mais lúdica de como ensinar as crianças com estas teorias. Porque isto eles não passam, só passam a teoria. Eles não passam uma forma lúdica de ensinar as crianças. Eu acho que isso peca um pouquinho na graduação. ( professor C)

[...] eu acho que principalmente, voltar mais os professores para a alfabetização. Há professores que entram na sala de aula e sabem como alfabetizar. Eles pegam alunos de inúmeras dificuldades, cada um diferentes do outro, e o professor ainda sem experiência nenhuma, é onde se sente angustiado, desesperado porque ele não sabe com trabalhar com aquele aluno. A teoria pode até ser boa, mas a prática é totalmente diferente. $O$ que eu acho que falta nos cursos que são voltados à educação, é voltar um pouco mais para a realidade, porque o que a gente vê nas escolas por aí é uma realidade bem diferente do que a gente estuda. Então acredito que a carga horária talvez seja boa, mas eu acho que deveria ser um pouco mais aproveitada e planejada um contato direto com a profissão que ele vai ter. (professor $\mathrm{D}$ )

Olha a carga horária do meu curso e as disciplinas eu achei eu não tenho que reclamar do meu curso eu achei que foi fantástico atendeu todas as demandas que eu precisava então em questão de se foi suficiente a graduação eu achei que foi perfeita de tudo, no ingresso de minha profissão acho que a disciplina que mais me ajudou foi a disciplina de psicologia eu acho que trabalha muito o dia a dia mas eu embora tenha sido bem trabalhada eu acho que foi pouco tempo tanto de psicologia quanto de didática porque na sala de aula to falando na faculdade é lindo é teórico mas no dia a dia é totalmente diferente então a parte de didática eu acho que deixou a desejar em qualquer curso. É o que nós mais trabalhamos, claro que a psicologia que tem no curso nos também trabalhamos mas é um lado totalmente diferente até mesmo o lado de não sei se vocês tem mas o lado de inclusão também eu acho que trabalha pouquíssimo e que precisa bastante eu fiz a minha pós eu trabalhei acho que o ano inteiro sobre inclusão então eu acho que é bem interessante que muitos professores ainda são muito leigos no caso de inclusão na verdade eu vou ser bem sincera eu não acho que existe tanto essa inclusão ainda é só um nome porque a inclusão em si ela é muito vaga. (professor $\mathrm{G}$ )

Percebe-se diante das falas dos docentes que, ainda não existe um equilíbrio entre a prática em sala de aula e as teorias da formação inicial, fato esse que se reflete na atuação profissional. Todavia, é preciso existir uma aproximação entre estes universos, que precisam dialogar entre si, por meio da interação entre teoria e prática, pois ambas se complementam. Para Imbernón (2011, p. 80):

A pesquisa deve ser entendida como ferramenta na formação do professor fundamentando-se na capacidade do professor em formular questões sobre sua própria prática, trabalhando em conjunto, 
compartilhando evidencias e informações enfrentando e buscando soluções para tais questões.

Assim, com base na insatisfação apresentada pelos docentes, sujeitos dessa pesquisa, entende-se que, as universidades ainda estão formando professores distantes da realidade da sala de aula. Segundo Nóvoa (2009), os princípios adotados na formação de professores raramente se concretizam pelo fato desta formação estar muito distante da profissão docente, de suas rotinas e culturas profissionais.

Desse modo, é importante que todo o profissional da educação tenha consciência sobre as suas práticas para agir frente a elas no ambiente educacional. Nessa direção, o mesmo autor chama atenção para a necessidade de se reconduzir o professor para o centro da cena educacional, reivindicando o regresso dos professores. Por isso a necessidade de uma formação de professores construída dentro da profissão. Fato este relatado pelo autor na seguinte afirmação: “A formação de professores deve passar para <dentro> da profissão, isto é, deve basear-se na aquisição de uma cultura profissional, concedendo aos professores mais experientes um papel central na formação dos mais jovens". (NÓVOA, 2009, p. 29)

Foi perguntado aos professores: 'A escola ofereceu cursos no âmbito da formação continuada? Se sim, você participou de algum deles? Quais? O que te levou a participar desses cursos, qual foi o motivador?'. No tocante a esse aspecto, a resposta foi unânime, todos os professores fizeram ou estão participando de algum curso de formação continuada. $\mathrm{O}$ que se pode confirmar pelas seguintes falas dos professores:

Do PNAIC, né? Na verdade não foi a escola né? Aqui a escola ela rege muito o que vem da ordem superior né? No caso assim, o curso mais... mais conhecido ultimamente é o que vem se falando do PNAIC, mesmo, né? (Perguntei a professora, se você participou quais, e o que te levou a participar desses cursos?) Ah! É outra coisa, PNAIC é para acrescentar o que você já possui né? Pra... é mais uma carga de conhecimento né? É sempre, não é nem pra você jogar fora o que você sabe, é para você agregar mesmo, né? Que venha contribuir mais com os seus conhecimentos, que venha somar né? Que você use para somar é [...] o que você já tem como bagagem. Muito bom o PNAIC. (Professor A)

[...] a escola não oferece. $O$ que oferece são os sindicatos. $O$ sindicato oferece vários cursos que você consegue fazer a sua pontuação. E aí você pode fazer. Eu fiz 'o de papel marchê', que faz os bonecos, eu achei muito legal, muito interessante, só que eu não consigo aplicar com as crianças na sala, porque são muitas crianças, então não dá pra se aplicar, são trinta crianças na sala, ainda você tem 
'necessidade especial', você tem criança que não tem laudo. Então, você não tem uma pessoa ali pra, sabe pra você falar: "Não, vamos lá, vamos ajudar! - Duas, três, não têm”. Então você tem que dar o conteúdo, você está numa sala de alfabetização, você tem que dar, você tem que cumprir a sua meta de alfabetização. Então você não consegue aplicar. Tem uns que são muito legais, mas eu não tive a oportunidade de fazer e ainda não tive tempo. (Professor C)

Por isso, a formação continuada também deve sustentar-se em constantes reflexões sobre a prática docente. É o que defende os autores Nóvoa e Imbernón. Para eles, os professores devem adquirir maior consciência de seu trabalho e de sua identidade por meio de registros, sobretudo, a formação que deve contribuir para que os docentes criem hábitos constantes de reflexão e autorreflexão.

Os docentes ao serem questionados consideram a formação continuada importante para sua atuação, todos julgam como necessária a prática do professor, como é possível identificar nas falas transcritas a seguir:

Com certeza. Cada dia é um problema novo, a cada dia é uma novidade, cada dia é um aluno com uma dificuldade. $O$ mundo está se desenvolvendo. Os alunos de hoje não são os mesmos alunos de vinte anos atrás. Hoje o conhecimento chega pra ele de uma forma diferente e muito mais rápido. Hoje eles têm um contato muito maior com a tecnologia. Hoje ele tem um contato muito maior com os meios de comunicação, e ele tem muito mais informação do que uma criança tinha há vinte anos atrás, até porque essa informação chega muito mais fácil pra ele. Se o professor não se atualizar, se o professor não saber como lidar com estas situações dentro da sala de aula vai se sentir perdido. E muitas vezes os alunos vão estar por dentro de assuntos que nem o professor sabe. Então a formação continuada é importante, saber métodos de como alfabetizar, saber métodos de como ter uma didática diferente dentro da sala de aula, de como trabalhar diferente, de como levar um conteúdo, usar novas tecnologias, usar esses recursos que hoje os alunos tanto têm interesse e prendem a atenção deles. Esses recursos que a gente tem que trazer pra sala de aula pra que possa prender a atenção deles voltado para a educação. Porque confessamos, cinco horas dentro de uma sala de aula, a criança sentada e escrevendo, é cansativo pra ele. Se o professor não tiver outros meios, não tiver uma renovação, vai se tornar dificil e ele vai se sentir incapaz. (Professor D)

Superimportante porque a partir do momento que eu começo a envolver outras pessoas no meu âmbito escolar eu digo as crianças eles fazem parte da minha vida e eu da vida deles então se eu paro eu não to tendo formação alguma então eu preciso dessa formação continuada para não passar somente informações pra passar experiências e quando eu passo só informação pelo menos é o que eu penso quando eu passo só a informação eu to formando personalidades imaturas quando eu passo conhecimento experiência 
eu to formando personalidades maduras então a formação continuada ela é parte da minha vida muito importante. (Professor F)

Jamais o professor deve se acomodar. O professor que tá acomodado ele não é nem pra... como que eu posso dizer... Não é nem pra, não existe a palavra reciclagem, sabe? Você jogar fora e pegar uma nova teoria, não é isso, é o que aconteceu mesmo com o PNAIC, é você agregar conhecimento, sabe você ouvir uma outra opinião, porque de uma... de uma opinião têm vários autores, cada um anda de um jeito, têm vários olhares né? Então assim, você, sim, deve, você deve tá sempre se atualizando, sempre com um livrinho embaixo do braço né? É tem um professor, que eu lembro que ele dizia la graduação, que o professor que tirar férias e não levar um livro, não é professor, (risos), ele tem... ele tem que tá sempre incomodado com isso, porque dentro da sala de aula têm muitos aspectos que a gente tem que se familiarizar.( Professor A)

A formação continuada apresenta-se então como fator importante para uma atuação profissional repleta de significados, o que possibilita ao docente maior aprofundamento dos conhecimentos profissionais, de modo que o docente que participa de atividades de formação continuada consegue refletir sobre sua prática. Assim, foi questionado os professores se sentiram necessidade de procurar cursos de aperfeiçoamento, além dos que foram indicados e oportunizados pela escola - e sim quais e por quê. Sobre essa questão eles responderam:

Cursos, eu sinto (necessidade) e pretendo fazer cursos principalmente voltados para alfabetizar. É muito discutido o construtivismos e método tradicional, e muitas vezes os professores não sabem como trabalhar, ou com um ou com outro. Nós sabemos que a rede pede mais o construtivismo, e muitas vezes você pergunta para o professor o que é o construtivismo, ele não sabe te explicar. Então eu acho que há necessidade sim de procurar mais cursos. Precisa procurar e a gente precisa estar envolvidos, e principalmente estar discutindo entre os professores, isso é uma falta que há de diálogo entre os professores dentro das escolas. Creio que todos que estão alí já são funcionários públicos, têm suas carreiras andando, uns com mais tempo, outros com menos, mas o que eles deveriam fazer é uma comunicação maior, uma troca de ideias maior, de repente um está fazendo um curso e passar para o outro: 'Oh, aprendi tal coisa nova!', pra se interessar. Esse diálogo dentro da escola é muito importante, precisa ser feito. Então cursos, são sempre sim uma oportunidade, se for possivel abraçar pra ter novos conhecimentos. E juntos, acho que podemos também ter essa opinião de compartilhar conhecimentos com nossos colegas de carreira e que estão conosco. (Professor D)

Então... eu fiz curso de extensão de Educação Infantil, é... fiz de Alfabetização, o PNAIC, e de Inclusão Social. E ainda fico muito incomodada com essas ofertas, que graças a Deus, não tem só um 
ano, no outro ano repete o curso, então você pode pegar ele depois no ano que vem pra você dar conta, né? Mas na sala de aula, são tantos aspectos, são tantos fatores, que você tem que se atualizar você tem que tá por dentro daquilo, pra você se ajudar, porque você precisa tá preparada né? Pra situações, você precisa ajudar o aluno, porque essa é tua função. (Professor A)

Sim, eu procurei alguns cursos. É importante a gente se reciclar pra poder acompanhar as crianças. Então a gente não consegue acompanhar o andamento delas, e nem consegue acompanhar o diaa-dia também delas porque elas não são só a escola, você tem que entrar no ambiente familiar com elas, porque as vezes a criança não aprende, por que ela têm dificuldade para aprender ou por que ela passando por alguma coisa na família? Então, acho que tudo isso também está incluído a criança. Então eu acho que tem sim que procurar, tem que se aperfeiçoar, se reciclando. Procurar pra fazer outros cursos voltados pra educação, lógico, que é importante. (Professor C)

Dessa forma, entende-se que, os processos de formação continuada de professores lhes propiciam ter maior consciência das delimitações da ação pedagógica, assim como a busca pela autonomia em sua atuação docente. Ressalta-se ainda que, a formação continuada apresenta-se, então, como um processo inacabado e inerente a profissão docente.

\section{Autonomia e trabalho em equipe}

A autonomia é um dos fatores de reivindicação que está presente no discurso pedagógico, no entanto, grande parte dos docentes não tem clareza de seu real significado, sendo este, um importante instrumento para uma gestão democrática e um elemento essencial para sua profissionalização. Para tanto, os professores devem exercer sua autonomia desde seu processo formativo garantindo que haja mudanças conceituais e das condições subjetivas e objetivas da profissão docente, levantando questões que permitam associar teoria e prática reconhecendo o papel social da profissão.

Segundo Gomes (2009, p.47), "Nos debates atuais nessa área, parece haver um reconhecimento de que, em princípio, os cursos que formam professores no Brasil, [...] ainda se mostram academicistas, distantes das práticas requeridas para o trabalho [...]”.

Sendo assim, é necessário que o profissional compartilhe conhecimentos e tenha autonomia de pensamento possibilitando a construção e criação de novos saberes, que possam ser protagonistas de suas práticas, a fim de se concretizar uma melhoria na educação. Diante do exposto, a formação inicial constitui-se como parte essencial, pois 
se trata do primeiro contato com o campo profissional, e o estágio é uma das possibilidades de reflexão sobre a práxis e a ação profissional.

Quando questionados se houve momentos de participação / autonomia na tomada de decisões no que diz respeito às propostas / ações da escola; para alguns professores entrevistados a autonomia está presente em apenas algumas decisões tomadas pela escola, e que em sua maioria não são tão relevantes no que diz respeito a ações e propostas pedagógicas, como presente nas seguintes falas dos professores entrevistados:

[...] nos momentos do coletivo, de ações que envolvem o coletivo, festas, essas coisas assim, as opiniões são validas, e sempre aceitou bem. (Professor B)

[...] ]em relação às festas que eles dão mais liberdade da gente querer participar ou não. Se vai ter um lanche para os alunos, se a gente quer ir ou não. Mas em relação às ações assim específicas... ". Marcela está dando problema... o que a gente pode fazer com ela?”, ou, “- Vamos fazer um projeto com uma visão mais ampla..." Isso não.(Professor E)

[...] sim, sempre que possível nossa opinião é ouvida e participamos muito das ações da escola, mas a equipe gestora é quem media isso e dependendo da proposta da ação não nos cabe participar na tomada de decisões. (Professor $\mathrm{G}$ )

Nesse contexto percebe-se que os docentes têm um papel muito reduzido no momento da tomada de decisões no sistema escolar, como afirma Pérez Gómez (2001), que os docentes trabalham isolados, distantes e em clima de rivalidade com os colegas de profissão, não há troca de conhecimentos e experiências, consequentemente sofrem a desvalorização social e econômica.

Os professores entrevistados foram submetidos à seguinte questão: "Qual sua percepção sobre os materiais didáticos adotados e utilizados pela escola? Em algum momento você participou das discussões acerca da escolha do material didático adotado pela escola?’. Diante das respostas obtidas foi possível notar que a maioria deles não teve participação na tomada de decisão acerca dos materiais didáticos. O que se pode observar nas respostas de alguns deles:

Não tive reunião nenhuma sobre o material a ser utilizado. Inclusive o material a ser utilizado, os livros didáticos, chegaram três meses depois na escola. Nesse período eu levava tudo da minha casa, eu buscava nos livros que eu tenho, pela internet, eu levava o meu 
material, eu imprimia. Nunca pedi xerox na escola. A gente pedia e tinha uma cota muito pequena, então eu nunca pedi porque nunca era em dia. $O$ desenvolvimento do material, eu acho que não é adequado porque os alunos ainda não estão no nível que o material pede, mas eu procuro utilizar alguns recursos que têm devido às minhas aulas, mas não todos. Mas em nenhum momento, a equipe gestora, nem coordenação, chegou pra discutir o material a ser utilizado. (Professor D)

Da particular sim. Da particular a gente tem essa possibilidade de estar escolhendo e de estar avaliando o material para as crianças. Da prefeitura não. Da prefeitura, é a própria prefeitura que decide como vão vir os livros, e muitas vezes os livros vêm com conteúdos que realmente não se encaixam para a idade deles. Que está muito atrasado ou está muito adiantado. Ou nem aqui, nem lá. Não tem nada do que se enquadra as vezes no plano pedagógico nosso. E aí fica difícil trabalhar com as crianças. Então a gente tem que tentar se virar, arrumar folhas, fazer Xerox, pra tentar encaixar o nosso plano com as crianças porque é muito difícil realmente o material aqui da prefeitura. (Professor C)

Assim, a autonomia está diretamente ligada ao exercício da profissão e não pode ser entendida como uma medida centralizadora e autoritária, mas sim, como, decisões que devem ser partilhadas por meio da colaboração e da responsabilidade coletiva.

Outro aspecto de fundamental importância no desenvolvimento profissional docente diz respeito ao trabalho em equipe, uma vez que, para fazer parte do grupo de profissionais da educação, o professor precisa da ajuda de seus pares, bem como também poder auxiliá-los. Quando todos os envolvidos no processo ensinoaprendizagem estão a par dos acontecimentos da comunidade educativa, tem consciência dos problemas que esta enfrenta, e elaboram estratégias para possíveis soluções, certamente as chances de obtenção de resultados positivos são muito maiores.

Em se tratando do assunto 'trabalho em equipe', Nóvoa (2009, p.31) defende que "[...] a formação dos professores deve valorizar o trabalho em equipe e o exercício coletivo da profissão, reforçando a importância dos projetos educativos da escola". Neste sentido, a escola tem o papel de viabilizar momentos em que os professores possam partilhar suas práticas, estimulando o exercício da reflexão sobre sua atuação, com o objetivo de transformar as experiências do coletivo em conhecimento profissional. Nesse sentido, sentimos a importância de se estimular também uma postura ética profissional construída através do diálogo entre os colegas de profissão.

Os professores entrevistados, ao serem questionados se no ingresso da profissão, se sentiram acolhidos e tiveram apoio por parte dos colegas professores e pela equipe 
gestora, as respostas obtidas foram bem diversificadas, o que aponta algumas falhas no processo de acolhida do professor iniciante na escola. Fato que se pode perceber por meio das seguintes respostas:

Sim. A primeira escola que eu entrei realmente eu tive muito acolhimento e todos me ajudaram, todos me incentivaram, todos me colocaram pra cima falando que a gente conseguia mudar, que a gente conseguia reverter o quadro em que as crianças estavam. Eu tive muito apoio de todos os profissionais.. (Professor C)

Em contrapartida, a resposta pelo professor D foi a seguinte:

Pelos professores, a minoria. Pela equipe gestora, não fui acolhido. Por professores, foram eles que me ajudaram, alguns, que são poucos, que me ajudam até hoje. Eu trabalho numa escola grande, com um número grande de funcionários, e se eu disser que foram três ou quatro funcionários, de quarenta, cinquenta, são os que me ajudam até hoje. Em relação à equipe gestora, quase não tenho contato. A parte de coordenação pouco pergunta pra mim o que acontece, não acompanha as minhas aulas. E simplesmente quando eu cheguei, no primeiro dia que eu ingressei, eu tive que correr atrás e perguntar aonde, o que eu tinha que fazer, pra onde eu tinha que ir, porque em nenhum momento alguém chegou e me instruiu nada. Então eu fui aprendendo com o tempo, sozinho e observando o que os outros professores faziam.

Eu tive apoio dos professores, me ajudaram em tudo o que eu precisava, sempre do meu lado. Mas em relação á equipe gestora, de sentar comigo e falar assim: "-- $\hat{O}$, na Prefeitura a gente faz desse jeito... você precisa saber disso...”. Não. Mas sim dos professores, sempre. (Professor E)

Dessa forma, percebe-se que, quando os professores se sentem acolhidos e trabalham juntos, há uma troca de aprendizagens com seus pares, que devem ser considerados. É o que defende Imbernón (2011), ao dizer que, se os professores trabalharem de forma integrada, poderão um aprender com o outro, compartilhando ideias, possibilidades de trabalho, dúvidas e buscando soluções coletivamente, ou seja, em parceria.

\section{Identidade profissional em construção}

Um dos fatores que contribuem para a construção da identidade profissional é a formação inicial. De acordo com Imbernón (2011, p. 60), “A formação inicial deve fornecer as bases para poder construir esse conhecimento pedagógico especializado." 
Desse modo, a formação inicial de professores deve preparar os futuros docentes para o começo da socialização profissional, além de fornecer subsídios teóricos e práticos, inerentes ao exercício pleno da profissão.

Outro fator determinante é que deve-se considerar o contexto histórico social e cultural do indivíduo, as relações e troca de experiências com seus pares, e o sentimento de pertença em um determinado grupo, pois estes contribuem e interferem diretamente nas escolhas e percepções que são construídas ao longo da vida.

Para Gomes (2009, p. 42):

Sentir-se apoiado, incentivado nos desafios que a vida apresenta, num cenário de aceitação e confiança, faz muita diferença nas relações humanas; por consequência, expressões, gestos de empatia e de solidariedade profissional contribuem sobremaneira nos processos indenitários (pessoais e profissionais).

Sendo assim, os professores entrevistados apresentaram as seguintes impressões ao ingressar na carreira docente:

Quando a gente faz faculdade a gente pensa que é uma certa coisa né. A gente vê um mundo totalmente diferente. E quando a gente entra numa sala de aula a gente vê que a realidade realmente é outra. Tudo o que a gente tem na faculdade, as teoria, tudo servem sim pra alguma coisa, mas quando entra na sala de aula, temos que colocar a mão na massa. Então a gente acaba levando um susto por ver até como a educação hoje em dia está. Não é do jeito que nós esperávamos. Tá muito pior do que deveria estar. E a cada dia a gente tenta fazer um pouquinho melhor pra ver se melhora, mas tá muito difícil, e a gente realmente toma um susto quando a gente entra uma sala de aula. ( Professor C)

Bom a gente tem aquele sonho né, pensa que tudo é perfeito, que a gente tem tudo aquela, como que fala toda uma ideologia puxa você vai conseguir salvar o mundo, conseguir consertar alguém ajudar na formação das pessoas né, no caso dos nossos alunos essa foi minha primeira impressão mas depois mudou tudo quando a gente já tá se ingressando já tá vivendo toda aquela profissão que a gente idealizou pensou e lutou em fazer mas depois tudo muda a realidade é outra. (Professor H)

De acordo com as falas, percebe-se uma expectativa e um sentimento inicial de admiração pela profissão durante a escolha e certo desapontamento e frustração diante as dificuldades encontradas no dia a dia, devido as possíveis lacunas deixadas durante a formação inicial. 
Além do mais ainda há a ideia da profissão vista como uma vocação, como um serviço que visa à melhoria da sociedade, bem como a justiça e a equidade, ao contrário do que é defendido pelos autores no que diz respeito à docência como profissão e não como missão. Significa dizer que, assumir-se como profissional depende de um processo social, político e histórico e necessita de um avanço na valorização e reconhecimento da profissão.

\section{Considerações finais}

Por meio deste trabalho, é possível identificar algumas fragilidades referentes à formação de educadores e o insucesso no seu ingresso às escolas. Uma fragilidade identificada foi a falta de reconhecimento da identidade profissional do educador, de não assumir-se como profissional e da ausência de reflexão, o que requer um avanço conceitual que possibilite superar vocações e misticismos relativos a atividade da docência.

$\mathrm{O}$ isolamento docente, facilmente identificado nas falas dos professores entrevistados, representa um dos aspectos que levam ao insucesso da formação e da prática reflexiva. Indiscutivelmente, a reflexão consiste em uma potencial alternativa para mudança na prática profissional, a ser trabalhada desde a formação inicial, assim como o conhecimento dos saberes tidos como necessários à prática desta profissão.

No tocante à prática da reflexão alguns aspectos foram identificados: a reflexão como auxilio ao professor sobre seu ensino com o objetivo de reproduzir melhor um currículo como um método; as limitações do processo reflexivo para questões técnicas de métodos de ensino e ignora analises de seus fins; a reflexão sobre o seu próprio ensino e sobre os estudantes desconsiderando as condições sociais da educação escolar que influenciam dentro da sala de aula e, por último, a reflexão que os professores fazem sobre si mesmos e seu trabalho, de tal modo que não venham a considerar seus problemas como exclusivamente seus, levando ao esgotamento e fragilização docente.

Cabe destacar que, a reflexão por si só não tem muito significado, é preciso considerar o que e como queremos que os professores reflitam e que a reflexão precisa gerar ação, ou seja, mudanças, transformações: pessoais, processuais e contextuais.

Todavia, faz-se necessário que os cursos de formação de professores, ao elaborar seus currículos e organizar suas práticas considerem as demandas das escolas e de seus 
professores, aproximando esses dois universos: o da formação profissional e o da atuação profissional. Universos estes que precisam dialogar por meio da articulação entre elementos teóricos e práticos, compreendendo-os como igualmente complementares um ao outro e não como elementos díspares.

Conclui-se enaltecendo o papel da formação inicial como estimuladora de uma prática reflexiva, bem como de definir e estabelecer os saberes tidos como necessários à prática da profissão docente, uma vez que constitui etapa fundante no processo de construção da identidade profissional.

\section{REFERÊNCIAS}

GOMES, M. O. Formação de professores na educação infantil. São Paulo: Cortez, 2009.

IMBERNÓN, F. Formação docente e profissional: formar-se para a mudança e a incerteza. 9. ed. São Paulo: Cortez, 2011.

NÓVOA, A. Para uma formação de professores construída dentro da profissão. In: Professores: Imagens do futuro presente. Lisboa: Educa: 2009, p.25-45.

PÉREZ GÓMEZ, A. I. A cultura escolar na sociedade neoliberal. Porto Alegre: Artmed, 2001.

ROLDÃO, M. C. N. Profissionalidade docente: o tempo e o modo de uma transformação. In: PINHO, S. Z (Org). Formação de educadores: dilemas contemporâneos. São Paulo: Unesp, 2011.

TARDIF, M. Saberes profissionais dos professores e conhecimentos universitários: elementos para uma epistemologia da prática profissional dos professores e suas consequências em relação à formação para o magistério. Revista Brasileira de Educação. Rio de Janeiro, n. 13, jan./fev./mar./abril, 2000.

ZEICHNER, K. M. Uma análise crítica sobre a "reflexão" como conceito estruturante na formação docente. Educação \& Sociedade. Campinas, vol. 29, n. 103, maio/ago. 2008. 


\section{Como referenciar este artigo}

DELGADO, Adriana Patrício et al. Desenvolvimento profissional docente: a formação inicial em foco. Temas em Educ. e Saúde, Araraquara, v.13, n.1, p. 74-92, jan./jun. 2017. DOI <https://doi.org/10.26673/rtes.v13.n1.jan-jun2017.6.9619>. ISSN: 15177947.

Submetido em: 09/05/2017

Aprovado em: 20/08/2017 